\title{
The cognitive effect of university classroom geometry. A virtual reality study focused on memory and attention.
}

\author{
Juan Luis Higuera-Trujillo ${ }^{a c}$, Carmen Llinares Millán ${ }^{a c}$, Antoni Montañana i Aviñóac, \\ Jorge Torres Cueco ${ }^{b}$, Carla Sentieri Omarrementeria ${ }^{b}$ \\ ${ }^{a}$ Universitat Politècnica de València-ETSIE, ${ }^{b}$ Universitat Politècnica de València-ETSA, \\ ${ }^{\mathrm{c}}$ Universitat Politècnica de València-I3B.
}

\begin{abstract}
Space influences our cognitive-emotional state. In teaching spaces, with a considerable effect on performance. Many design variables are involved. Among them, geometry has been traditionally less explored despite its usual prominence in design, due to the complexity of its modification in existing physical classrooms. However, today this can be addressed through the use of virtual reality. This was the objective of the present study: to contribute to the study of the cognitive effect of different geometry parameters applied in a university classroom. It was tackled through a laboratory field study carried out with 80 university students. The geometry variable was studied through two parameters: ceiling height (3 settings) and width (3 settings) of the university classroom. The 9 combinations were implemented in a virtual reality. The cognitive effect was explored through memory and attention performances. Both of them, quantified through auditory psychological tasks: the former, using a list of words to memorize; and the latter, using a computer program to measure reaction times and errors. Analyses indicate that memory and attention can be affected by some of the geometry parameters. This suggests that they may be especially relevant in the design of university classrooms, which is of interest to the different agents involved in the university classroom project and design.
\end{abstract}

Keywords: Virtual reality, university classrooms, geometry, memory, attention.

\section{Introduction}

Many studies have shown that physical stimuli in the classroom can influence the cognitive functions that determine learning, memory, and attention (Choi et al., 2014). These 
important effects have led to a growing interest in analysing the relationship between physical environment and learning (Yang et al., 2013). However, this relationship is complex due to its multidimensional nature (Higgins et al. 2005).

Currently, there are hardly any works that have analysed the effect that spatial attributes of the classroom, such as size or shape, have on student performance, unlike the multitude of works that have analysed the effect of environmental attributes such as temperature, air quality, acoustics and lighting, because these are more standardized by industry technical codes (Roskos and Neuman, 2011; Yang et al., 2013). Thus, Ahrentzen and Evans (1984) found that the height of the classroom ceiling was positively correlated with teacher satisfaction, also causing a decrease in the perception of crowding. On the other hand, Read et al. (1999) showed that the lower ceilings affected the cooperative behaviour of the students, generating higher levels of cooperation in the classrooms. Earthman (2004) noted that classrooms with high ceilings could negate the benefit of better lighting and increase acoustic problems due to reverberation. In any case, there are no concrete classroom studies that specifically analyse another variable related to volume, such as width or how it influences student learning. Therefore, although changing height and/or width might be proposed as a way to add value, it is difficult to be sure, based on the evidence, in which direction it should be altered, in addition to the high cost that it would entail.

From a methodological point of view, most of these works have been carried out in real classrooms. This implies that a classroom had to be selected and all the variables involved in the study had to be modified (Marchand et al., 2014), or they had to select a series of them with different design characteristics and compare the results. obtained (Yang et al., 2013). Using real classrooms has two important limitations, on the one hand the high cost of modifying certain design variables, such as those that influence the volume of the space, and on the other hand the difficulty of perfectly controlling the study conditions. Thus, it seems necessary to find a way to analyse these spatial attributes of the classroom and their impact on the cognitive functions of the students, allowing the possibility of isolating the effect of a certain variable without incurring the high cost of modifying the classroom or the complexity of locate real classrooms of a specific design.

In this sense, virtual reality (VR) generates simulation environments that allow precise control of 3D space presentations, helping end users in the evaluation of different design alternatives. Thus, these presentations can be altered in the dynamic way of user responses within possible interactions, behavioural monitoring, and recording of functional and cognitive performance (Rizzo et al., 2006). Rizzo et al., (2006) and Iriarte et al. (2012) used virtual classrooms to evaluate attention problems and suggest that these environments would be considered as a more efficient and profitable tool to carry out the measurement of attention performance using traditional tools 
In this context, the objective of this work is to analyse the impact that the width and height of the classroom have on two fundamental cognitive functions: attention and memory. For this, virtual environments will be used since they allow greater control over the different spatial factors, allowing rapid changes in visual stimuli, thus overcoming the limited configurations that are generally present when real spaces are used.

\section{Materials and Methods}

A laboratory fieldwork was developed. Participants performed psychological tasks focused on memory and attention performance during immersion in virtual classrooms (Figure 1).

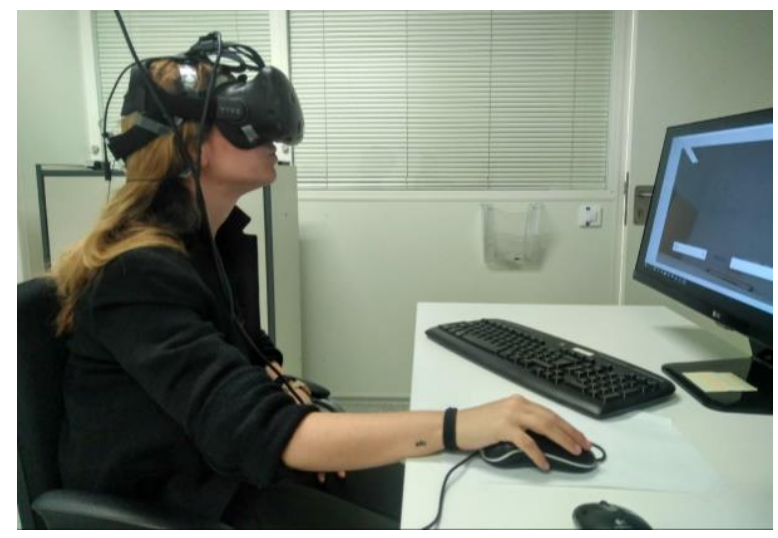

Fig. 1: Participant during the psychological tasks.

Source: own elaboration.

\subsection{Participants}

The study was conducted with 80 participants. The sample was gender-balanced (40 women and 40 men) and the average age was $22.52(\sigma=5.752)$. Regarding the inclusion criteria, three aspects were established: (1) being a university student, (2) being Spanish (to avoid possible cultural effects), and (3) having normal or corrected-to-normal vision with contact lenses without colour deficiencies.

\subsection{Classroom}

A real physical classroom was used as a base. Its virtual replica was made, and different configurations were implemented on this. Two parameters were studied: (1) "ceiling 
height"; and (2) "width". The configurations of each one were: for ceiling height (1a) "X m", (1b) "X-0.6 m", and (1c) "X-1.2 m"; for width (2a) "X m", (2b) "X-0.6 m"; and (2c) "X-1.2 m". Where $\mathrm{X}$ and $\mathrm{Y}$ were the original dimensions of the classroom: $\mathrm{X}$ was the height $(2.60 \mathrm{~m})$, and $\mathrm{Y}$ was the width $(8.80 \mathrm{~m})$. The combination of these resulted in nine simulations (Figure 2). All of them were rendered in $360^{\circ}$ format and showed using the head-mounted device HTC Vive". Specifically, the base classroom was one from the Higher Technical School of Building Engineering (ETSIE) of the Universitat Politècnica de València.

\subsection{Psychological records}

The psychological tasks were focused on quantify memory and attention performances.

\subsubsection{Memory task}

The psychological memory task consisted on remembering the 15 words of three prerecorded lists (45 total words). The participant had to repeat the words of each list in a 30 seconds a time limit. The next list was then listened, until the task was finished. The number of words remembered was taken as a quantification of memory. This task is similar to the DRM paradigm tests (Beato and Díez 2011).

\subsubsection{Attention task}

The psychological attention task consisted on reacting as soon as possible to specific auditory stimuli (24 objectives) and to avoid others (96 distractors). All these stimuli were shown randomly, with a minimum of $800 \mathrm{~ms}$ and a maximum of $1600 \mathrm{~ms}$. The reaction time was taken as the attention quantification. This task is similar to the continuous auditory performance tests (Seidman et al. 1998).

\subsection{Data processing}

The statistical analysis were carried out using IBM SPSS v.16.0 software, once the database was collected and anonymized. 


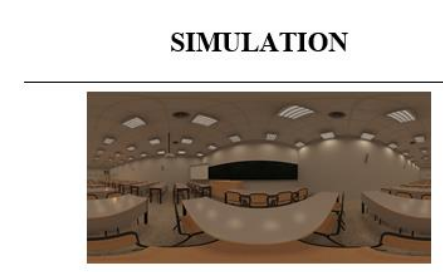

\section{CEILING WIDTH}

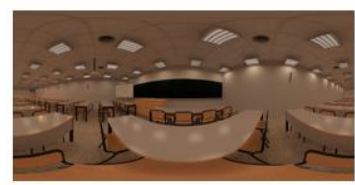

$\mathrm{X} \quad \mathrm{X}$

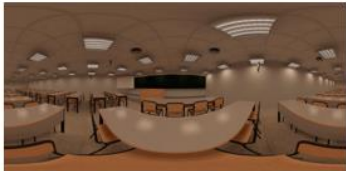

$\mathrm{X}-0.6 \quad \mathrm{X}$

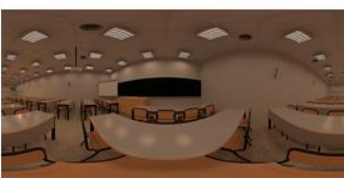

$\mathrm{X}-1.2 \quad \mathrm{X}$

$\mathrm{X} \quad \mathrm{X}-0.6$

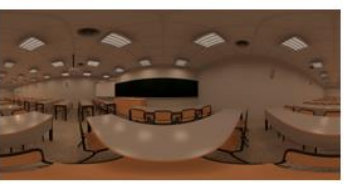

$\mathrm{X}-0.6 \quad \mathrm{X}-0.6$

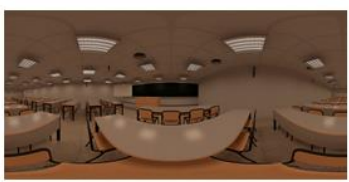

$\mathrm{X}-1.2 \quad \mathrm{X}-0.6$

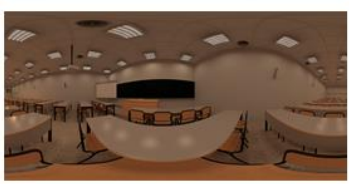

$\mathrm{X} \quad \mathrm{X}-1.2$

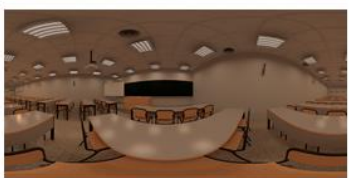

$\mathrm{X}-0.6 \quad \mathrm{X}-1.2$

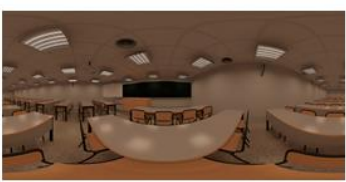

$\mathrm{X}-1.2 \quad \mathrm{X}-1.2$

Fig. 2: Geometry simulations. Source: own elaboration. 


\section{Results}

Results are organized in the following sections: (3.1) distribution of the variables; and (3.2) influence of geometry on memory and attention performance.

\subsection{Variable distribution}

First, the distribution of the variables was checked. The Kolmogorov-Smirnov test shows that memory $(p=0.091)$ and attention $(p=0.546)$ followed a normal distribution. The differences for each of the design variables are analysed using ANOVA test.

\subsection{Influence of geometry on memory and attention performance}

Analyses carried out allowed quantifying the effect of geometry on memory and attention. Figure 3 shows the results obtained. The results are presented below, differentiating each of the two parameters: ceiling height and width.

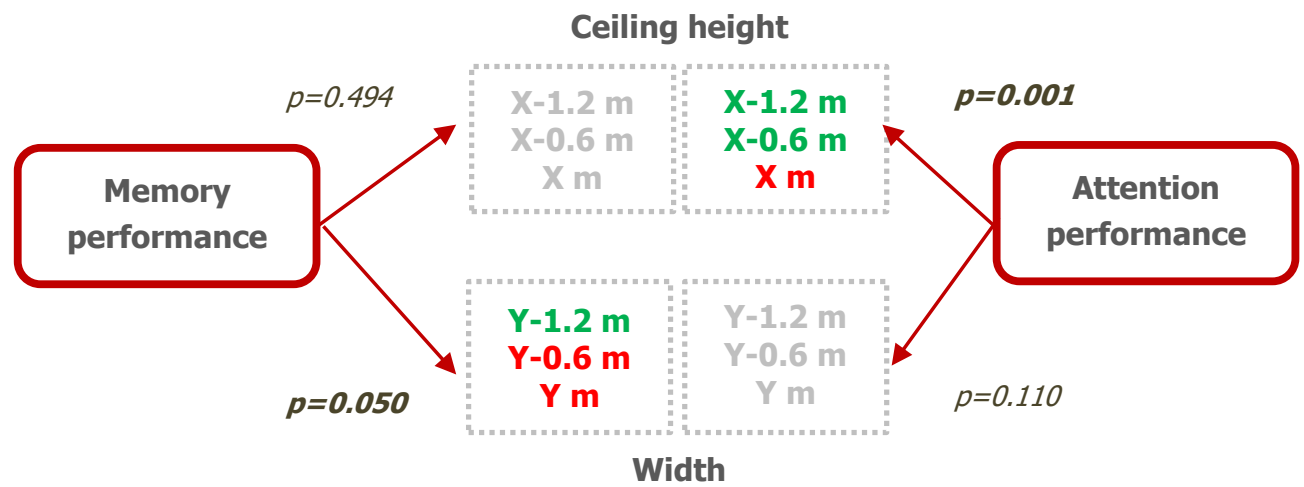

Fig. 3: Significant differences in memory and attention tasks. Green and red highlight the best and worst results, respectively.

Source: own elaboration.

\subsubsection{Ceiling height}

Different ceiling height dimensions have a significant impact on attention performance $(\mathrm{p}=0.001)$. The $\mathrm{X}-1.2 \mathrm{~m}$ and $\mathrm{X}-0.6 \mathrm{~m}$ dimensions generates the best results. However, ceiling height have not impact on memory performance $(p=0.494)$. 


\subsubsection{Width}

Different width dimensions have a significant impact on memory performance $(p=0.050)$ but has no impact on attention performance $(p=0.110)$. The width dimension that generates the best results in memory is $\mathrm{Y}-1.2 \mathrm{~m}$.

\section{Conclusions}

Analyses indicate that geometry affects the memory and attention performances. It could be suggested that although attention and memory depend on different spatial parameters, there are common patters: smaller spaces (in ceiling height and width) are more appropriate.

The width of the classroom has a significant influence on the development of memory tasks. Specifically, the smaller the width, the better the performance of the memory task. In the same way, the height of the ceiling influences attention, so that the lower the ceiling, the shorter the reaction time and therefore the better the performance of the attention task.

Both geometric parameters are therefore fundamental in the design of the classroom because they affect basic cognitive functions of leaning. These results are of interest to all professionals related to teaching spaces: from teachers and researchers to designers and policy makers responsible for teaching spaces.

\section{Acknowledgments}

This work was supported by the Ministerio de Economía, Industria y Competitividad of Spain (Project BIA2017-86157-R, and PRE2018-084051)

\section{References}

Ahrentzen, S., \& Evans, G. W. (1984). Distraction, privacy, and classroom design. Environment and Behavior, 16(4), 437-454.

Beato, M. S., and E. Díez. 2011. False Recognition Production Indexes in Spanish for 60 DRM Lists with Three Critical Words.” Behavior Research Methods, 43(2): 499-507.

Choi, H. H., Van Merriënboer, J. J., \& Paas, F. (2014). Effects of the physical environment on cognitive load and learning: towards a new model of cognitive load. Educational Psychology Review, 26(2), 225-244.

Earthman, G. I. (2004). Prioritization of 31 criteria for school building adequacy. Baltimore, MD: American Civil Liberties Union Foundation of Maryland 
Higgins, S., Wall, K., Mccaughey, C., Woolner, P., \& Hall, E. (2005). The Impact of School Environments. Newcastle, UK: University of Newcastle.

Iriarte, Y., Diaz-Orueta, U., Cueto, E., Irazustabarrena, P., Banterla, F., \& Climent, G. (2012). AULA-Advanced virtual reality tool for the assessment of attention: Normative study in Spain. Journal of Attention Disorders, 20(6), 542-568.

Marchand, G. C., Nardi, N. M., Reynolds, D., \& Pamoukov, S. (2014). The impact of the classroom built environment on student perceptions and learning. Journal of Environmental Psychology, 40 187-197.

Read, M. A., Sugawara, A. I., \& Brandt, J. A. (1999). Impact of space and color in the physical environment on preschool children's cooperative behavior. Environment and Behavior, 31(3),413-428.

Rizzo, A. A., Bowerly, T., Buckwalter, J. G., Klimchuk, D., Mitura, R., \& Parsons, T. D. (2006). A virtual reality scenario for all seasons: the virtual classroom. Cns Spectrums, 11(1), 35-44.

Roskos, K., \& Neuman, S. B. (2011). The classroom environment: First, last, and always. The Reading Teacher, 65(2), 110-114.

Seidman, L. J., H. C. Breiter, J. M. Goodman, J. M. Goldstein, P. W. Woodruff, K. O’Craven, B. R. Rosen, M. T. Tsuang, and B. R. Rosen. 1998. A Functional Magnetic Resonance Imaging Study of Auditory Vigilance with Low and High Information Processing Demand." Neuropsychology, 12 (4): 505-18.

Yang, Z., Becerik-Gerber, B., \& Mino, L. (2013). A study on student perceptions of higher education classrooms: Impact of classroom attributes on student satisfaction and performance. Building and Environment, 70, 171-188. 